\title{
Comparison of Ticagrelor with Clopidogrel in Reducing Interleukin-17 and Myeloperoxidase Expression in Thrombus and Improving Postprocedural Coronary Flow in ST-segment Elevation Myocardial Infarction Patients
}

\author{
Wen Hua Li; Song Qi Guo; Shu Wang; Xin Sun; ZhuQin Li; Xin Yong Sun; Yan Ming Sun; Lan Feng Wang; Wei Pan \\ Department of Cardiology, The First Affiliated Hospital of Harbin Medical University, Nangang District, Heilongjiang \\ Province, Harbin, China.
}

Received, March 5, 2018; Revised, May 2, 2018; Accepted, May 9, 2018; Published, May 10, 2018.

\begin{abstract}
Purpose. This study aimed to explore the effects of ticagrelor (a P2Y12 receptor inhibitor) on interleukin (IL)-17 and myeloperoxidase (MPO) expression in coronary thrombus as well as on the coronary blood flow in ST-segment elevation myocardial infarction (STEMI) patients following percutaneous coronary intervention (PCI). Methods. Forty STEMI patients who were admitted to the First Affiliated Hospital of Harbin Medical University between August 1, 2014 and December 30, 2014 were enrolled in this study according to a set inclusion criteria. They were randomized to ticagrelor and clopidogrel groups and treated with $180 \mathrm{mg}$ ticagrelor and $600 \mathrm{mg}$ clopidogrel before PCI, respectively. Intracoronary thrombus aspiration was performed by a physician during PCI. Immunohistochemistry and Western blot analysis were carried out to detect the expression of IL-17 and MPO in the thrombus. Corrected thrombolysis in myocardial infarction frame count (CTFC) was used to evaluate blood flow after PCI. Results. Immunohistochemistry results showed that the average positive staining area percentage of IL-17 and MPO in the clopidogrel group was significantly higher than that in the ticagrelor group. Western blot analysis also showed similar results for IL-17 (clopidogrel $0.71 \pm 0.036$, ticagrelor $0.50 \pm 0.56$ ) and MPO (clopidogrel $0.50 \pm 0.040$; ticagrelor $0.38 \pm 0.06$ ). CTFC was lower in the ticagrelor group than that in the clopidogrel group $(\mathrm{P}<0.05)$. Conclusions. Ticagrelor is more effective than clopidogrel in reducing inflammation thrombosis and improving postprocedural PCI blood flow in STEMI patients.
\end{abstract}

This article is open to POST-PUBLICATION REVIEW. Registered readers (see "For Readers") may comment by clicking on ABSTRACT on the issue's contents page.

\section{INTRODUCTION}

Acute coronary syndrome (ACS) usually results from one of the following three problems: unstable angina (38\%), ST-segment elevation myocardial infarction (STEMI, 30\%), or non-ST-segment elevation myocardial infarction $(25 \%)(1)$. In the United States, approximately 780,000 people receive a diagnosis of ACS and 17,255 receive a diagnosis of STEMI annually $(2,3)$. Emergency primary percutaneous coronary intervention (PCI) is currently the primary treatment of choice for STEMI (4) because the coronaryartery can be quickly opened to prevent cardiomyocyte necrosis. However, after PCI, STEMI still exhibits a prothrombotic state due to platelet activation (5). The activated platelets play an important role in coronary atherosclerosis and ACS by adhering to the endothelial cells, aggregating in the vascular wall, and releasing platelet granules to induce chronic coronary atherosclerotic plaque rupture, thrombus formation, vascular occlusion, and blood flow change $(6,7)$. Platelet activation is mediated by G-protein coupled adenosine diphosphate (ADP) receptors $\mathrm{P} 2 \mathrm{Y} 1$ and $\mathrm{P} 2 \mathrm{Y} 12$ (8). P2Y12 is reported to play a vital role in platelet aggregation (9). Therefore, P2Y12 inhibitors or P2Y12 receptor antagonists may be pivotal in the treatment of ACS. Dual-antiplatelet therapy with aspirin and thienopyridines (prasugrel, ticlopidine, and clopidogrel), which bind to $\mathrm{P} 2 \mathrm{Y} 12$ receptors, has shown great efficacy in the treatment of patients with $\operatorname{ACS}(10,11)$.

Corresponding Author: Wei Pan, Department of Cardiology, The First Affiliated Hospital of Harbin Medical University, Nangang District, Heilongjiang Province, Harbin 150001, China. Email: tianyeyey@hotmail.com 
Clopidogrel is a classic antiplatelet drug and irreversible P2Y12 antagonist. Ticagrelor, a novel oral P2Y12 receptor antagonist, can reversibly bind to P2Y12 receptor without undergoing biotransformation (12). A Platelet Inhibition and Patient Outcomes study proved that compared with clopidogrel, ticagrelor is more effective in reducing major adverse cardiac events, cardiovascular mortality, and all-cause mortality in patients with STEMI after the administration of low-dose aspirin (13). Several studies attribute the pathogenesis of STEMI to the thrombotic complications induced by atherosclerosis. However, in 2013, Libby suggested that inflammation plays a crucial role in ACS (14). Inflammatory cell infiltration can promote plaque rupture and accelerate thrombosis $(15,16)$. Thus, the administration of anti-inflammatory agents following PCI is critical for STEMI patients. However, the effect of ticagrelor on inflammatory cell infiltration in thrombus is unclear.

Interleukin (IL)-17 and myeloperoxidase (MPO) are two inflammatory biomarkers in ACS (17). IL-17 is produced by unconventional $\mathrm{T}$ cells and appears to regulate local tissue inflammation via the coordinated expression of chemokines and proinflammatory cytokines. Recent animal studies suggested thepro-atherogenic role of IL-17 $(18,19)$. IL-17 is highly expressed in patients with coronary and symptomatic carotid atherosclerotic lesions, which can induce the production of pre-inflammatory mediators (20). Released from the human polymorphonuclear neutrophils, MPO has been suggested to play an important role in inflammatory vascular diseases (21). Therefore, we clinically investigated the effects of ticagrelor on IL-17 and MPO expression in coronary artery thrombus and the blood flow change in STEMI patients with PCI, relative to clopidogrel.

\section{MATERIALS AND METHODS}

This study was approved by the Ethics Committee of the First Hospital of Harbin Medical University. All patients provided written informed consent.

\section{Patients}

The participants for this study were selected from a group of individuals reported with acute STEMI from April 1, 2014 to December 30, 2014 at the Cardiology Department of the First Hospital of the Harbin Medical University, Harbin, China. The inclusion criteria for this study were as follows: 1) the participants were women who were not in the gestation period or men; 2) age range of 18-79 years; 3) persistence of myocardial infarction symptoms for more than $30 \mathrm{~min}$; 4) arrival at the hospital within $24 \mathrm{~h}$ after the onset of chest pain; 5) the ST segment was the elevation at the admission time; and 6) patients who were intended to receive emergency PCI. Additionally, before admission, patients would be asked in detail whether they took acetylsalicylic acid (aspirin). If the patient regularly took acetylsalicylic acid (aspirin) before admission, he or she would not been given acetylsalicylic acid (aspirin) before operation. If the patient did not take aspirin, he (she) would be given loading dose (300 $\mathrm{mg}$ ) of acetylsalicylic acid (aspirin) to rule out the impact of aspirin.

However, the exclusion criteria were as follows: patients 1) who had accepted P2Y12 receptor antagonist treatment within the past 30 days; 2) who were allergic to clopidogrel or ticagrelor; 3) who had administeredoral anticoagulants; 4) who used platelet IIb/IIIa inhibitors within the past 7 days; 5) who had a history of intracranial hemorrhage; and 6) who had severe cardiac or renal insufficiency.

\section{Random allocation}

According to the inclusion and exclusion criteria, 40 acute STEMI patients, including 25 men and 15 women were enrolled in this study. They were randomly divided into two groups according to the treatment regimens as follows: ticagrelor $(\mathrm{n}=20)$ and clopidogrel groups $(n=20)$. Before PCI, the patients in the ticagrelor group were orally administered ticagrelor (loading dose, $180 \mathrm{mg}$ ) and aspirin (loading dose, $300 \mathrm{mg}$ ), while patients in the clopidogrel group were administered clopidogrel (loading dose, $600 \mathrm{mg}$ ) and acetylsalicylic acid (aspirin) (loading dose, $300 \mathrm{mg}$ ).

All patients underwent venous blood tests for hypersensitive C-reactive protein (HsCRP), and routine blood tests for blood lipid, random blood glucose, myocardial enzymes, and myocardial calcium protein I ( $\mathrm{TnI})$. The hemodynamics of the coronary artery after emergency PCI was observed by three cardiologists who were blinded to the administration of the drugs. The corrected thrombolysis in myocardial infarction frame count (CTFC) was recorded.

\section{PCI procedures}

First, a radial artery sheath was placed through the radial artery. Under the guidance of a loach guide wire, the angiography catheter was loaded in the coronary ostium of the left and right coronary arteries through the radial artery sheath. Culprit 
vessels were found through coronary radiography. Next, thrombus aspiration was performed to remove the thrombus and open the vessels. A stent was applied if there was $75 \%$ or more stenosis, while the procedure was ended if there was $<75 \%$ stenosis. The procedure of thrombus aspiration was as follows: a catheter was loaded under the guidance of a guide wire. The guide wire was introduced into the vessel lumenat the distal end of the stenosis via a catheter for repeated suction. During the procedure, radiography was performed to check whether the thrombus was clearly aspirated (22).

\section{Pathological section}

Thrombus aspiration in the coronary artery of STEMI patients during PCI is shown in Figure 1. The thrombus was washed with normal saline and stored in $4 \%$ paraformaldehyde solution. Six hours later, the tissues were dehydrated with a graded series of sugar solution (10, 20, and 30\%). During this process, sugar solution at higher concentration was added when the tissue samples were deposited in a sugar solution of lower concentration. The samples were repeatedly rinsed with water, and then dehydrated in graded ethanol solutions (50$100 \%$ ). The samples were cleared twice in xylene solution for $0.5 \mathrm{~h}$ till hyaline and then embedded in paraffin. The tissues were then sliced into $5 \mu \mathrm{m}$ sections.

\section{Immunohistochemistry}

For immunohistochemical staining, paraffin-embedded sections were baked at $60^{\circ} \mathrm{C}$ for $120 \mathrm{~min}$ and dewaxed in xylene solution. The sections were hydrated in graded ethanol solutions followed by incubation with $3 \%$ hydrogen peroxide $\left(\mathrm{H}_{2} \mathrm{O}_{2}\right)$ for $30 \mathrm{~min}$ at room temperature to block the activity of endogenous peroxidases. Antigen retrieval was performed by heating in a microwave oven. The sections were then incubated with primary antibodies (IL-17 antibody and MPO antibodies, Abcam, USA) at $4^{\circ} \mathrm{C}$ overnight. After washing in phosphate-buffered saline (PBS) three times, the secondary antibody was added and incubated at $37^{\circ} \mathrm{C}$ for $30-60 \mathrm{~min}$. The sections were developed with DAB. Then, they were counterstained with hematoxylin, dehydrated, hyalinized, and mounted. After drying, the sections were observed under IX70 optical microscope (Olympus, Tokyo, Japan). The positively stained area was claybank. Five random positive fields were selected for the quantification of the average positive staining area percentage (APSAP) (23).

\section{Western blot}

The thrombus tissues $(50 \mathrm{mg})$ were pulverized and lysed in 30-50 $\mu \mathrm{L}$ lysis buffers for $30 \mathrm{~min}$ on ice. They were centrifuged $\left(12,000 \mathrm{rpm}, 4^{\circ} \mathrm{C}, 5 \mathrm{~min}\right)$, and the supernatant was used for protein quantification by using BCA kit. The samples with $30 \mu \mathrm{g}$ proteins were loaded onto sodium dodecyl sulphate polyacrylamide gel (SDS-PAGE). The proteins were transferred from the gel to a membrane, stained with Ponceau, and blocked. The membrane was incubated with primary antibodies (anti-IL-17 and anti-MPO antibodies, abcam, USA). Then, the secondary antibody was added, followed by exposure, development, and fixing. The bands were analysed by Image Pro Plus software. $\beta$-actin was used as an internal reference (24).

\section{STATISTICAL ANALYSIS}

All statistical analyses were performed using SPSS 19.0 software (Chicago, IL, USA). Data were presented as the mean \pm standard deviation (SD). Measurement data were analysed using Student's $t$-test, while numeration data (clinical data) were analysed by $\chi^{2}$ test. $P<0.05$ was defined as statistically significant.

\section{RESULTS}

\section{Characteristics of STEMI patients}

The characteristics of 40 STEMI patients are listed in Table 1. There was no statistical difference in basic clinical data, including sex, age, duration of chest pain symptoms, time between the oral drugs and PCI, reperfusion time, preprocedural oral statins, preprocedural low molecular heparin/common heparin, history of hypertension, diabetes, smoking, and old myocardial infarction, as well as laboratory data (HsCRP, WBC, neutrophilic granulocyte percentage, absolute neutrophil count, monocyte number, neutrophils/lymphocytes, random blood sugar) between the clopidogrel and ticagrelor groups. In addition, there was no significant difference in postprocedural clinical data, such as Killip, ejection fraction, culprit vessel-related factors, blood lipid, preprocedural cardiac enzyme, postprocedural blood, and postprocedural cardiac enzyme between the two groups (Table 2). 
Table 1 Characteristics of ST-segment elevation myocardial infarction (STEMI) patients.

\begin{tabular}{|c|c|c|c|}
\hline Clinical characteristics & Clopidogrel $(\mathrm{n}=20)$ & Ticagrelor $(\mathrm{n}=20)$ & $P$ \\
\hline Male & $13(65 \%)$ & $12(60 \%)$ & 0.74 \\
\hline Age (years) & $59.45 \pm 10.98$ & $58.54 \pm 16.48$ & 0.88 \\
\hline \multicolumn{4}{|l|}{ Relevant cardiovascular risk factors } \\
\hline Hypertension history & $11(55 \%)$ & $10(50 \%)$ & 0.75 \\
\hline Diabetes history & $7(35 \%)$ & $8(40 \%)$ & 0.74 \\
\hline Smoking history & $12(60 \%)$ & $10(50 \%)$ & 0.52 \\
\hline OMI history & $4(20 \%)$ & $5(25 \%)$ & 0.70 \\
\hline Duration of chest pain symptoms, $\mathrm{h}$ & $2.81 \pm 0.78$ & $2.63 \pm 0.86$ & 0.71 \\
\hline Orally administered drugs to the time of PCI, min & $85.27 \pm 15.67$ & $80.81 \pm 18.84$ & 0.11 \\
\hline Reperfusion time, $\min ^{1}$ & $289 \pm 89.05$ & $284 \pm 74.07$ & 0.66 \\
\hline Preprocedural oral statins ${ }^{2}$ & $18(90 \%)$ & $17(85 \%)$ & 0.63 \\
\hline Preprocedural low molecular heparin/common heparin & $12(60 \%)$ & $14(70 \%)$ & 0.50 \\
\hline \multicolumn{4}{|l|}{ Laboratory data (preoperative urgent inspection) } \\
\hline $\mathrm{HsCRP}, \mathrm{mg} / \mathrm{L}$ & $34.05 \pm 6.38$ & $30.83 \pm 7.96$ & 0.056 \\
\hline WBC counts, $10^{9} / \mathrm{L}$ & $12.34 \pm 4.30$ & $11.42 \pm 3.11$ & 0.57 \\
\hline Neutrophil granulocyte percentage, $\%$ & $79.89 \pm 8.51$ & $83.06 \pm 6.31$ & 0.33 \\
\hline Absolute neutrophil count, $10^{9} / \mathrm{L}$ & $10.03 \pm 4.09$ & $9.54 \pm 2.84$ & 0.74 \\
\hline Monocyte, $10^{9} / \mathrm{L}$ & $0.54 \pm 0.14$ & $0.47 \pm 0.13$ & 0.54 \\
\hline Neutrophils/lymphocytes & $11.26 \pm 3.65$ & $9.46 \pm 1.68$ & 0.78 \\
\hline Random blood sugar, mmol/L & $9.27 \pm 2.75$ & $7.26 \pm 1.70$ & 0.053 \\
\hline
\end{tabular}

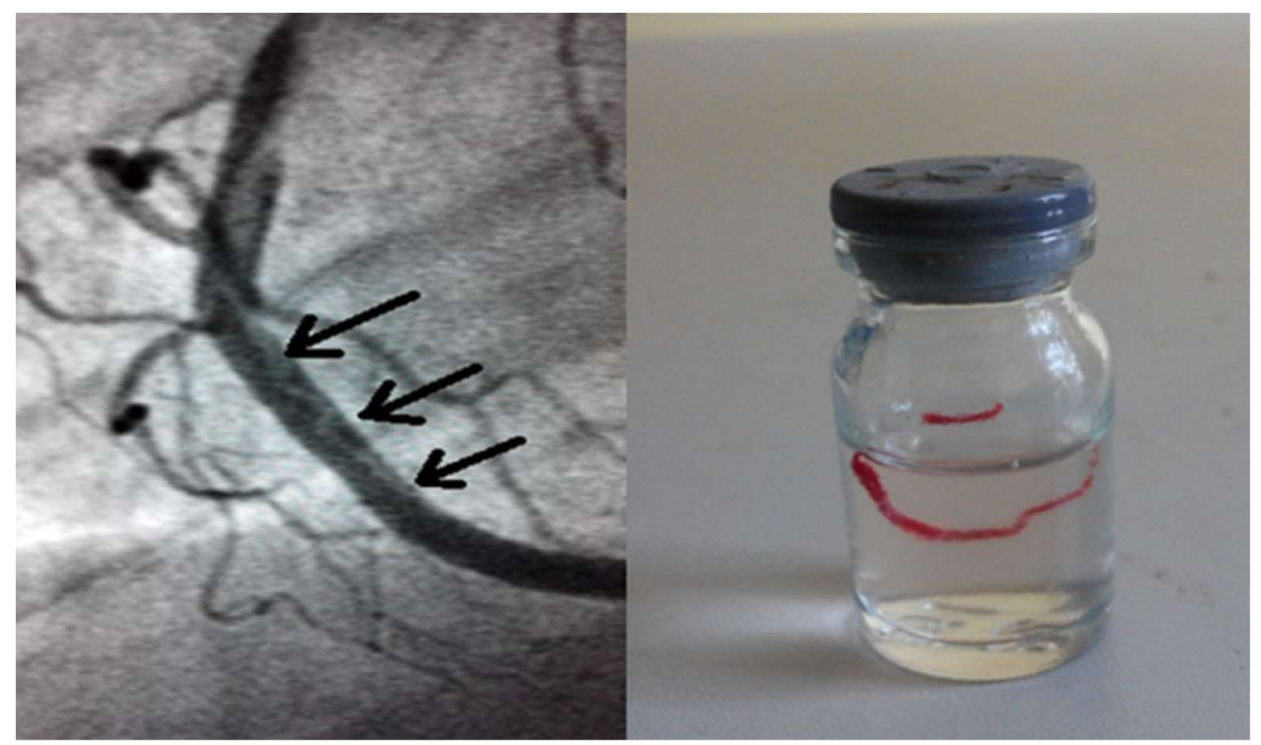

Figure 1 Intracoronary thrombosis in percutaneous coronary intervention (PCI) (arrow). 
Table 2 Postprocedural clinical statistics of ST-segment elevation myocardial infarction (STEMI) patients.

\begin{tabular}{|c|c|c|c|}
\hline & Clopidogrel $(n=20)$ & Ticagrelor $(n=20)$ & $P$ \\
\hline Killip $\geq$ grade II & $6(30 \%)$ & $7(35 \%)$ & 0.73 \\
\hline Ejection fraction & $48.54 \pm 7.81$ & $53.27 \pm 6.0$ & 0.12 \\
\hline \multicolumn{4}{|l|}{ Culprit vessel } \\
\hline Left anterior descending coronary artery & $7(35 \%)$ & $9(45 \%)$ & 0.51 \\
\hline Left circumflex & $6(30 \%)$ & $5(25 \%)$ & 0.72 \\
\hline Right coronary artery (RCA) & $7(35 \%)$ & $6(30 \%)$ & 0.73 \\
\hline Intraprocedural application of temporary pacemaker & $6(30 \%)$ & $4(20 \%)$ & 0.46 \\
\hline Intraprocedural application of intra-aortic ballon pump & $4(20 \%)$ & $3(15 \%)$ & 0.67 \\
\hline Total cholesterol ,mmol/L & $4.38 \pm 0.99$ & $4.45 \pm 0.73$ & 0.86 \\
\hline Total triglyceride, $\mathrm{mmol} / \mathrm{L}$ & $1.55 \pm 0.51$ & $1.46 \pm 0.63$ & 0.71 \\
\hline High density lipoprotein, mmol/L & $1.09 \pm 0.18$ & $1.05 \pm 0.23$ & 0.68 \\
\hline Low density lipoprotein, $\mathrm{mmol} / \mathrm{L}$ & $2.99 \pm 0.97$ & $3.10 \pm 0.63$ & 0.76 \\
\hline \multicolumn{4}{|l|}{ Preprocedural cardiac enzyme } \\
\hline Creatine kinase, $\mathrm{U} / \mathrm{L}$ & $303.5 \pm 10.8$ & $294.36 \pm 16.37$ & 0.39 \\
\hline $\mathrm{CK}$ isoenzyme, $\mathrm{U} / \mathrm{L}$ & $60.6 \pm 11.4$ & $55.72 \pm 15.40$ & 0.13 \\
\hline Preprocedural cardiac troponin, $\mathrm{ng} / \mathrm{ml}$ & $8.58 \pm 19.21$ & $6.87 \pm 4.95$ & 0.16 \\
\hline \multicolumn{4}{|l|}{ Postprocedural blood } \\
\hline Hypersensitive C-reactive protein & $52.49 \pm 11.53$ & $37.83 \pm 10.25$ & 0.11 \\
\hline White blood cell (WBC) counts $* 10^{9} / \mathrm{L}$ & $12.7 \pm 3.76$ & $10.66 \pm 1.53$ & 0.12 \\
\hline Neutrophil granulocyte percentage, \% & $82.91 \pm 7.17$ & $81.83 \pm 5.94$ & 0.7 \\
\hline Absolute neutrophil count $* 10^{9} / \mathrm{L}$ & $10.87 \pm 3.08$ & $8.84 \pm 1.58$ & 0.065 \\
\hline Monocyte number $* 10^{9} / \mathrm{L}$ & $0.73 \pm 0.21$ & $0.87 \pm 0.69$ & 0.53 \\
\hline Neutrophils/lymphocytes & $10.20 \pm 2.67$ & $8.76 \pm 1.25$ & 0.64 \\
\hline \multicolumn{4}{|l|}{ Postprocedural cardiac enzyme } \\
\hline $\mathrm{CK}_{\max } \mathrm{U} / \mathrm{L}$ & $3204.8 \pm 251.06$ & $2939.32 \pm 157.6$ & 0.64 \\
\hline $\mathrm{CK}-\mathrm{MB}_{\max } \mathrm{U} / \mathrm{L}$ & $212.73 \pm 15.13$ & $309.43 \pm 21.33$ & 0.22 \\
\hline Before discharge blood C-reactive protein & $7.83 \pm 9.79$ & $4.48 \pm 2.50$ & 0.28 \\
\hline
\end{tabular}

Expression of $\mathrm{IL}-17$ and MPO detected by immunohistochemistry and Western blot analysis The results of immunohistochemistry are displayed in Figure 2. IL-17 and MPO were mainly detected in the plasma of inflammatory cells (eosinophils, plasma cells, and neutrophils). The expression of IL-17 and MPO in the clopidogrel group was significantly higher than that in the ticagrelor group. The APSAPs of IL-17 and MPO in the clopidogrel group were much higher (IL-17, $10.99 \pm 3.20$; MPO, $8.21 \pm 1.71)$ than those in the ticagrelor group (IL-17, $4.36 \pm 1.30$; MPO, $4.31 \pm 1.16)(P<$ $0.05)$.

\section{Evaluation of PCI postprocedural coronary blood flow by CTFC}

The coronary blood flow after PCI procedure was evaluated to 30 frames/s CTFC (normal). The results showed that CTFC was reduced to $23.55 \pm$ 3.71 and $26.86 \pm 1.69$ in the ticagrelor and clopidogrel group, respectively. There was a significant difference between the two groups $(P<$ $0.05)$.

\section{Following up}

We conducted regular and rigorous follow-up visits to both groups of patients, and the outcome was significantly better in Ticagrelor group than that in the clopidogrel group, regardless of the symptoms and related auxiliary examinations. 


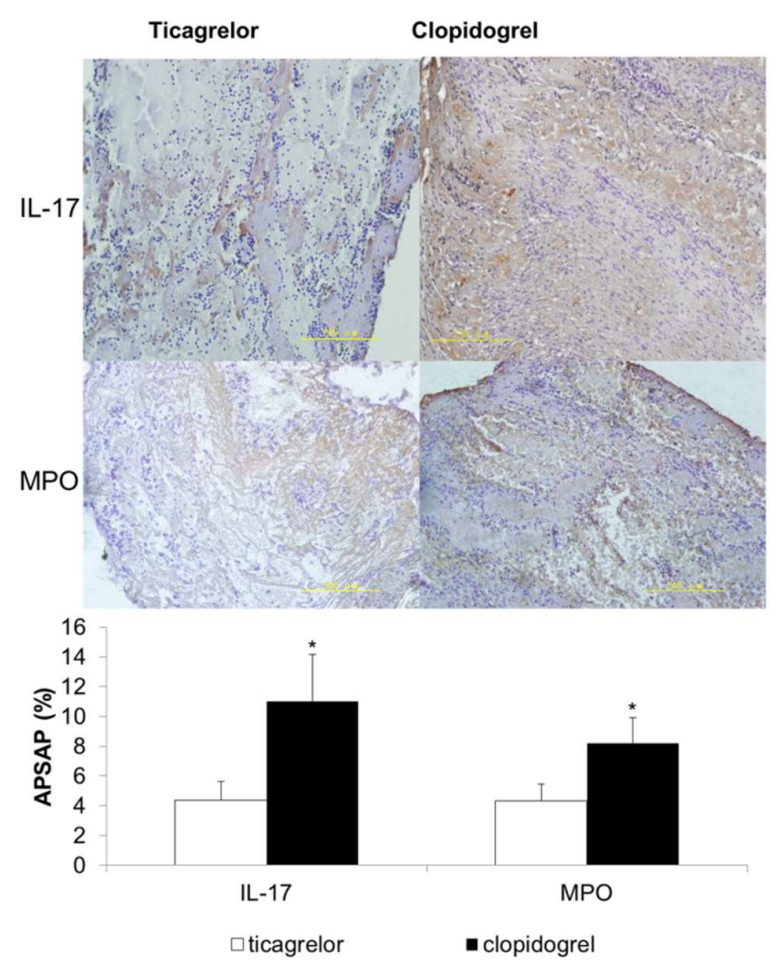

Figure 2 Detection of interleukin 17 (IL-17) and myeloperoxidase (MPO) expression in thrombus by immunohistochemistry in the ticagrelor and clopidogrel groups $(200 \mathrm{X})$. APSAP: average positive staining area percentage. $\mathrm{n}=20$ for each group, $* P<0.05$ between two groups using Student's t-test.

Similarly, Western blot analysis also showed that the expression of IL-17 and MPO in the clopidogrel group (IL-17, $0.71 \pm 0.036 ;$ MPO, $0.50 \pm 0.07$ ) was significantly higher than that in the ticagrelor group $(\mathrm{IL}-17,0.50 \pm 0.040 ; \mathrm{MPO}, 0.38 \pm 0.06)(P<0.05)$ (Figure 3).

\section{DISCUSSION}

Inflammation plays a significant role in STEMI. The present study proved that ticagrelor was more effective in exerting anti-inflammatory effect and improving blood flow than clopidogrel. The ticagrelor group showed significantly lower IL-17 and MPO expression in thrombus, as well as significantly lower CTFC than the clopidogrel group. Ticagrelor exerts anti-inflammatory effects during thrombus formation (25). The stronger antiplatelet effect of ticagrelor reduces platelet-leukocyte aggregate formation as well as inflammation (25).

IL-17 is a specific cytokine generated by the helper T lymphocytes, Th17.
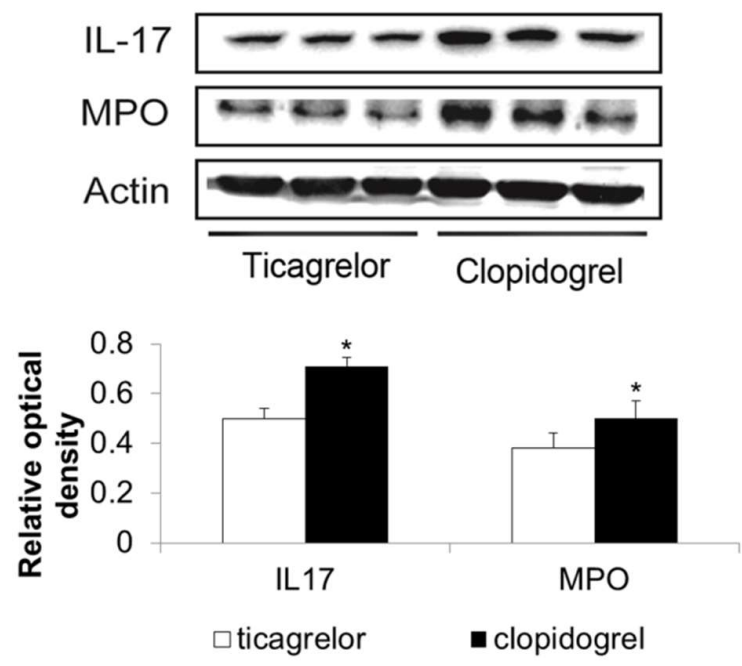

Figure 3 Detection of interleukin 17 (IL-17) and myeloperoxidase (MPO) expression in thrombus by Western blotting in the ticagrelorand clopidogrel groups. $\mathrm{n}=20$ for each group, ${ }^{*} P<0.05$ between two groups using Student's t-test.

Previous studies have shown that the Th17 cells positively contributed to auto-immune disorders and inflammation via production of proinflammatory IL-17 (26). Zhao et al. reported that Th17 activation existed in unstable angina and acute myocardial infarction, which might aggravate systemic and plaque local inflammatory responses and promote plaque rupture, thereby further inducing unstable angina and acute myocardial infarction (27). Other scholars report that the balance of Th17/regulatory T cells (Treg) may be critical in the pathogenesis of plaque destabilization and onset of unstable angina and acute myocardial infarction $(28,29)$. In addition, Th17 cells and IL-17 expression were significantly increased, while Treg cells were markedly decreased in patients with ACS (30). IL-17 was found to mediate tissue infiltration and destruction by inducing the expression of chemokines, matrix metalloproteinases, and proinflammatory cytokines (31). The present study showed that ticagrelor significantly inhibited the expression of IL-17 compared to clopidogrel, which indicated that the ticagrelor was more effective in exerting anti-inflammatory effect in ACS.

MPO is a vascular inflammatory marker released to the blood by polymorphonuclear neutrophils (32). It has been reported to promote plaque formation through the production of free radicals and activation of platelets (33). Research 
has found that MPO deficient individuals have lower risk of CVD (34). Contemporary studies indicate that MPO is a novel predictive factor of adverse cardiac events in patients with ACS, especially for those with a lower level of troponin I $(35,36)$. High levels of inflammation in the thrombus of STEMI patients is closely related to incomplete ST-segment fall-back, worsened myocardial reperfusion, and higher ventricular remodelling risk (37). In the present study, the MPO level was significantly higher in the clopidogrel group than that in the ticagrelor group. MPO is released to the blood by activated neutrophil granulocytes and macrophages, which can oxidize low-density lipoprotein and induce red blood cell aggregation, resulting in arterial erythrocyte-rich thrombus (35). Therefore, we assumed that ticagrelor was more effective than clopidogrel in preventing vascular inflammation.

The present study confirmed the anti-inflammatory effects of clopidogrel. Clopidogrel might exert anti-inflammatory effects through the following mechanisms: first, by inhibiting the expression of P-selectin, CD40L, and tissue factors (38); second, by protecting the expression of endothelial nitric oxide synthase, which is restrained in the state of inflammation (39); third, by reducing $\mathrm{CD}^{+}$cells and the activity of key transcription factors in inflammation to achieve anti-inflammatory effects (40); finally, by inhibiting P2Y12 and inflammatory cytokines to release in neutrophils, lymphocytes, and macrophages (41). However, clopidogrel requires metabolism by the liver enzymes for its proper functioning, and it is affected by gene polymorphism, which limits its bioavailability (42). Ticagrelor is a novel oral antiplatelet drug that can reversibly bind to P2Y12 receptor. Notably, it does not require metabolism by the liver enzymes and is not affected by gene polymorphism (42). Therefore, for patients with no or low response to clopidogrel, ticagrelor can help prevent the occurrence of ischemic events better (43). The present study confirmed that compared with clopidogrel, ticagrelor decreased IL-17 and MPO levels in the thrombus, which indicated that ticagrelor can more potently inhibit inflammation to affect thrombogenesis by inhibiting P2Y12 receptors in the neutrophils, lymphocytes, and macrophages.

Our results were in accordance with some recent studies. Li et al. (44) compared the influence of ticagrelor and clopidogrel on inflammatory biomarkers and vascular endothelial function for patients receiving emergency PCI and demonstrated that ticagrelor could inhibit inflammation and improve vascular endothelial cell function to a greater extent than clopidogrel. Additionally, Park et al. (45) have revelaed that in patients with STEMI treated by primary PCI, a $180 \mathrm{mg}$ loading dose of ticagrelor is more effective in reducing microvascular injury than a $600 \mathrm{mg}$ loading dose of clopidogrel. A more recent study reported that compared to clopidogrel loading, ticagrelor loading before primary PCI was not associated with reduced myocardial infarct size during the first 48 hours (46), which was not in contradiction with our findings.

Evidence has shown that ticagrelor treatment significantly increased the concentration of adenosine, which can induce ischemic preconditioning in patients (47). Li et al. (48) also suggested that ticagrelor increased adenosine and cyclic adenosine monophosphate plasma concentrations compared with clopidogrel in patients with ACS. Adenosine-enhanced ischemic preconditioning plays an important role in the prevention of sudden cardiac death, reduction of myocardial infarction area, and inhibition of tumour cell growth (47). A recent meta-analysis performed by D'Ascenzo et al. (49) showed that ischemic preconditioning reduced the incidence of PMI following PCI. Preconditioning has been considered to stabilize vulnerable plaques via inhibition of platelet aggregation and thrombogenesis (50). Therefore, the anti-thrombosis effect of ticagrelor might be associated with ischemic preconditioning. However, more clinical data are necessary to clearly explain the association between them.

Inflammatory reaction in STEMI can attenuate the effect of PCI. Inflammatory cell infiltration promotes the formation and progression of thrombus (51, 52). Activated neutrophils and monocytes can change the structural and functional characteristics of red blood cells, increase red blood cell aggregation, and increase the activity of tissue factor expression, which results in thrombus formation and affects coronary blood flow (41). Previous studies have confirmed that more MPO-positive cells (neutrophils and macrophages) in the thrombus are pumped out from the arteries during PCI in patients with acute myocardial infarction, which is related to the worsening of postprocedural myocardial blood flow (53). Animal experiments and clinical studies have found that adenosine can reduce myocardial infarction area 
and improve left ventricular function and coronary blood flow (54). Ticagrelor not only inhibits adenosine deaminase, but also increases the concentration of adenosine (55) by inducing human red blood cells to release ATP, which is broken into adenosine. Reduction inthe mortality of patients with STEMI might be due tothe anti-inflammatory effects of ticagrelor.

However, the small sample size of this study, which is a major limitation, should be taken into account. Therefore, further study with large sample size is needed to confirm our results.

In conclusion, the results of this study primarily indicate that preprocedural administration of rapid and high-loading dose of ticagrelor $(180 \mathrm{mg}$ ) may significantly decrease the level of inflammatory cytokines in infarction-related artery thrombosis, when compared with clopidogrel therapy (loading dose, $600 \mathrm{mg}$ ). It addition, it may explain a part of the reduction in risk seen in Platelet Inhibition and Patient Outcomes.

\section{ACKNOWLEDGEMENTS}

This work was supported by the Department of Education of Q3279Heilongiiang Province (No. 12541428).

\section{CONFLICT OF INTEREST}

The authors declare that they have no competing interests.

\section{REFERENCES}

1. Braunwald E. Unstable angina and non-ST elevation myocardial infarction. American journal of respiratory and critical care medicine, 2012;185:924-932.

2. Go AS, Mozaffarian D, Roger VL, Benjamin EJ, Berry JD, Borden WB, Bravata DM, Dai S, Ford ES, Fox CS. Heart disease and stroke statistics--2013 update: a report from the American Heart Association. Circulation, 2013;127:e6.

3. Go AS, Mozaffarian D, Roger VL, Benjamin EJ, Berry JD, Blaha MJ, Dai S, Ford ES, Fox CS, Franco S, Fullerton HJ, Gillespie C, Hailpern SM, Heit JA, Howard VJ, Huffman MD, Judd SE, Kissela BM, Kittner SJ, Lackland DT, Lichtman JH, Lisabeth LD, Mackey RH, Magid DJ, Marcus GM, Marelli A, Matchar DB, McGuire DK, Mohler IER, Moy CS, Mussolino ME, Neumar RW, Nichol G, Pandey DK, Paynter NP, Reeves MJ, Sorlie PD, Stein J, Towfighi A, Turan TN, Virani SS, Wong ND, Woo D, Turner MB. Heart Disease and Stroke
Statistics - 2014 Update: A report from the American Heart Association. Circulation, 2014;129:e28-e292.

4. Ibanez B, Macaya C, Sánchez-Brunete V, Pizarro G, Fernández-Friera L, Mateos A, Fernández-Ortiz A, García-Ruiz JM, García-Álvarez A, Iñiguez A. Effect of early metoprolol on infarct size in ST-segment elevation myocardial infarction patients undergoing primary PCI: the METOCARD-CNIC Trial. Circulation, 2013:CIRCULATIONAHA. 113.003653 .

5. Alexopoulos D. P2Y12 inhibitors adjunctive to primary PCI therapy in STEMI: Fighting against the activated platelets. International Journal of Cardiology, 2013;163:249-255.

6. Kapoor JR. Platelet activation and atherothrombosis. N Engl J Med, 2008;358:1638.

7. Eikelboom JW, Hirsh J, Spencer FA, Baglin TP, Weitz JI. Antiplatelet drugs: antithrombotic therapy and prevention of thrombosis: American College of Chest Physicians evidence-based clinical practice guidelines. CHEST Journal, 2012;141:e89S-e119S.

8. Offermanns S. Activation of platelet function through $\mathrm{G}$ protein-coupled receptors. Circulation research, 2006;99:1293-1304.

9. Fontana P, Dupont A, Gandrille S, Bachelot-Loza C, Reny J-L, Aiach M, Gaussem P. Adenosine diphosphate-induced platelet aggregation is associated with P2Y12 gene sequence variations in healthy subjects. Circulation, 2003;108:989-995.

10. Grines CL, Bonow RO, Casey DE, Gardner TJ, Lockhart PB, Moliterno DJ, O'Gara P, Whitlow P. Prevention of premature discontinuation of dual antiplatelet therapy in patients with coronary artery stents: a science advisory from the American Heart Association, American College of Cardiology, Society for Cardiovascular Angiography and Interventions, American College of Surgeons, and American Dental Association, with representation from the American College of Physicians. Journal of the American College of Cardiology, 2007;49:734-739.

11. Feres F, Costa RA, Abizaid A, Leon MB, Marin-Neto JA, Botelho RV, King SB, Negoita M, Liu M, de Paula JET. Three vs twelve months of dual antiplatelet therapy after zotarolimus-eluting stents: the OPTIMIZE randomized trial. Jama, 2013;310:2510-2522.

12. Amsterdam EA, Wenger NK, Brindis RG, Casey DE, Jr., Ganiats TG, Holmes DR, Jr., Jaffe AS, Jneid H, Kelly RF, Kontos MC, Levine GN, Liebson PR, Mukherjee D, Peterson ED, Sabatine MS, Smalling RW, Zieman SJ. 2014 AHA/ACC Guideline for the Management of Patients with Non-ST-Elevation Acute Coronary Syndromes: a report of the American College of Cardiology/American Heart Association Task Force on Practice Guidelines. J Am Coll Cardiol, 2014;64:e139-228. Epub 
2014/09/28.

13. Mahaffey KW, Wojdyla DM, Carroll K, Becker RC, Storey RF, Angiolillo DJ, Held C, Cannon CP, James S, Pieper KS. Ticagrelor compared with clopidogrel by geographic region in the Platelet Inhibition and Patient Outcomes (PLATO) trial. Circulation, 2011;124:544-554.

14. Libby P. Mechanisms of Acute Coronary Syndromes and Their Implications for Therapy. New England Journal of Medicine, 2013;368:2004-2013.

15. Silvestre J, Tedgui A. Atherosclerosis and related ischemic diseases: inflammation, the mixed blessing. Medicographia, 2014;36:355-361.

16. Silvestre-Roig C, de Winther MP, Weber C, Daemen MJ, Lutgens E, Soehnlein O. Atherosclerotic Plaque Destabilization Mechanisms, Models, and Therapeutic Strategies. Circulation research, 2014;114:214-226.

17. Liang J, Zheng ZM. Myeloperoxidase (MPO) and interleukin-17 (IL-17) plasma levels are increased in patients with acute coronary syndromes. Journal of International Medical Research, 2009;37:862-866.

18. Smith E, Prasad KMR, Butcher M, Dobrian A, Kolls JK, Ley K, Galkina E. Blockade of Interleukin-17A Results in Reduced Atherosclerosis in Apolipoprotein E-Deficient Mice. Circulation, 2010;121:1746-1755.

19. Zeng JQ, Xu YP, Wang DM, Gao SQ, Zou HY, Deng ZH. [Single nucleotide polymorphisms in 22 HLA-Cw alleles in Chinese Han population]. Hereditas, 2010;32:473-479.

20. Benagiano M, Munari F, Ciervo A, Amedei A, Paccani SR, Mancini F, Ferrari M, Della BC, Ulivi C, D'Elios S. Chlamydophila pneumoniae phospholipase D (CpPLD) drives Th17 inflammation in human atherosclerosis. Proceedings of the National Academy of Sciences, 2012;109:1222-1227.

21. Lau D, Baldus S. Myeloperoxidase and its contributory role in inflammatory vascular disease. Pharmacology [?] Therapeutics, 2006;111:16-26.

22. Torpy JM, Lynm C, Glass RM. Percutaneous coronary intervention. Jama, 2004;291:778-778.

23. Yao R, Ma Y, Du Y, Liao M, Li H, Liang W, Yuan J, $\mathrm{Ma} \mathrm{Z}, \mathrm{Yu} \mathrm{X}, \mathrm{Xiao} \mathrm{H}$. The altered expression of inflammation-related microRNAs with microRNA-155 expression correlates with Th17 differentiation in patients with acute coronary syndrome. Cellular \& Molecular Immunology, 2011;8:486-495.

24. Sugiyama S, Okada Y, Sukhova GK, Virmani R, Heinecke JW, Libby P. Macrophage myeloperoxidase regulation by granulocyte macrophage colony-stimulating factor in human atherosclerosis and implications in acute coronary syndromes. American Journal of Pathology, 2001;158:879-891.

25. Thomas MR, Storey RF. Effect of P2Y12 inhibitors on inflammation and immunity. Thrombosis \& Haemostasis, 2015;114:490-497.

26. Ouyang W, Kolls JK, Yan Z. The Biological Functions of T Helper 17 Cell Effector Cytokines in Inflammation. Immunity, 2008;28:454-467.

27. Zhao Z, Wu Y, Cheng M, Ji Y, Yang X, Liu P, Jia S, Yuan Z. Activation of Th17/Th1 and Th1, but not Th17, is associated with the acute cardiac event in patients with acute coronary syndrome. Atherosclerosis, 2011;217:518-524.

28. Li Q, Wang Y, Wang Y, Chen K, Zhou Q, Wei W, Wang Y. Treg/Th17 Ratio Acts as a Novel Indicator for Acute Coronary Syndrome. Cell biochemistry and biophysics, 2014;70:1489-1498.

29. Wyss CA, Neidhart M, Altwegg L, Spanaus KS, Yonekawa K, Wischnewsky MB, Corti R, Kucher N, Roffi M, Eberli FR. Cellular actors, Toll-like receptors, and local cytokine profile in acute coronary syndromes. European heart journal, 2010;31:1457-1469.

30. Cheng X, Yu X, Ding Y-j, Fu Q-q, Xie J-j, Tang T-t, Yao R, Chen Y, Liao Y-h. The Th17/Treg imbalance in patients with acute coronary syndrome. Clinical Immunology, 2008;127:89-97.

31. Kolls JK, Lindén A. Interleukin-17 Family Members and Inflammation. Immunity, 2004;21:467-476.

32. Klebanoff SJ. Myeloperoxidase: friend and foe. $\mathrm{J}$ Leukoc Biol, 2005;77:598-625. Epub 2005/02/04.

33. Zhang R, Brennan M-L, Fu X, Aviles RJ, Pearce GL, Penn MS, Topol EJ, Sprecher DL, Hazen SL. Association between myeloperoxidase levels and risk of coronary artery disease. Jama, 2001;286:2136-2142.

34. Nicholls SJ, Hazen SL. Myeloperoxidase, modified lipoproteins, and atherogenesis. Journal of lipid research, 2009;50:S346-S351.

35. Loria V, Dato I, Graziani F, Biasucci LM. Myeloperoxidase: a new biomarker of inflammation in ischemic heart disease and acute coronary syndromes. Mediators of inflammation, 2008;2008.

36. Sugiyama S, Okada Y, Sukhova GK, Virmani R, Heinecke JW, Libby P. Macrophage myeloperoxidase regulation by granulocyte macrophage colony-stimulating factor in human atherosclerosis and implications in acute coronary syndromes. The American journal of pathology, 2001;158:879-891.

37. Yunoki K, Naruko T, Sugioka K, Inaba M, Iwasa Y, Komatsu R, Itoh A, Haze K, Inoue T, Yoshiyama M. Erythrocyte-rich thrombus aspirated from patients with ST-elevation myocardial infarction: association with oxidative stress and its impact on myocardial reperfusion. European heart journal, 2012;33:1480-1490.

38. Ge H, Zhou Y, Liu X, Nie X, Wang Z, Guo Y, Chen W, Yang Q. Relationship between plasma inflammatory markers and platelet aggregation in patients with clopidogrel resistance after angioplasty. 
Angiology, 2012;63:62-66.

39. Heitzer T, Rudolph V, Schwedhelm E, Karstens M, Sydow K, Ortak M, Tschentscher P, Meinertz T, Böger R, Baldus S. Clopidogrel improves systemic endothelial nitric oxide bioavailability in patients with coronary artery disease evidence for antioxidant and antiinflammatory effects. Arteriosclerosis, thrombosis, and vascular biology, 2006;26:1648-1652.

40. Muhlestein JB. Effect of antiplatelet therapy on inflammatory markers in atherothrombotic patients. Thrombosis \& Haemostasis, 2010;19:71.

41. Zarbock A, Polanowska-Grabowska RK, Ley K. Platelet-neutrophil-interactions: Linking hemostasis and inflammation. Blood Reviews, 2007;21:99-111.

42. Capodanno D, Dharmashankar K, Angiolillo DJ. Mechanism of action and clinical development of ticagrelor, a novel platelet ADP P2Y12 receptor antagonist. 2010.

43. Van de Werf F, Bax J, Betriu A, Blomstrom-Lundqvist C, Crea F, Falk V, Filippatos G, Fox K, Huber K, Kastrati A, Rosengren A, Steg PG, Tubaro M, Verheugt F, Weidinger F, Weis M. Management of acute myocardial infarction in patients presenting with persistent ST-segment elevation: the Task Force on the Management of ST-Segment Elevation Acute Myocardial Infarction of the European Society of Cardiology. Eur Heart J, 2008;29:2909-2945. Epub 2008/11/14.

44. Li Z, Li Y, Zhang T, Miao W, Su G. Comparison of the influence of ticagrelor and clopidogrel on inflammatory biomarkers and vascular endothelial function for patients with ST-segment elevation myocardial infarction receiving emergency percutaneous coronary intervention: study protocol for a randomized controlled trial. Trials, 2016;17:75.

45. Park SD, Lee MJ, Baek YS, Kwon SW, Shin SH, Woo SI, Kim DH, Kwan J, Park KS. Randomised trial to compare a protective effect of Clopidogrel Versus TIcagrelor on coronary Microvascular injury in ST-segment Elevation myocardial infarction (CV-TIME trial). Eurointervention Journal of Europcr in Collaboration with the Working Group on Interventional Cardiology of the European Society of Cardiology, 2016;12:e964.

46. Yun KH, Rhee SJ, Ko JS. Comparison of the Infarct Size between the Loading of Ticagrelor and Clopidogrel in Patients with Acute Myocardial Infarction Undergoing Primary Percutaneous Coronary Intervention. Korean Circ J, 2017;47:705-713.

47. Mccully JD, Toyoda Y, Uematsu M, Stewart RD, Levitsky S. Adenosine-enhanced ischemic preconditioning: adenosine receptor involvement during ischemia and reperfusion. Ajp Heart \& Circulatory Physiology, 2001;280:H591-602.

48. Li X, Wang Q, Xue Y, Chen J, Lv Q. Ticagrelor Compared with Clopidogrel Increased Adenosine and Cyclic Adenosine Monophosphate Plasma Concentration in Acute Coronary Syndrome Patients. Basic \& Clinical Pharmacology \& Toxicology, 2017; 120:610-614.

49. D'Ascenzo F, Moretti C, Omedè P, Cerrato E, Cavallero E, Er F, Presutti DG, Colombo F, Crimi G, Conrotto F. Cardiac remote ischaemic preconditioning reduces periprocedural myocardial infarction for patients undergoing percutaneous coronary interventions: a meta-analysis of randomised clinical trials. Eurointervention Journal of Europcr in Collaboration with the Working Group on Interventional Cardiology of the European Society of Cardiology, 2014;9:1463-1471.

50. Babu GG, Walker JM, Yellon DM, Hausenloy DJ. Peri-procedural myocardial injury during percutaneous coronary intervention: an important target for cardioprotection. European Heart Journal, 2011;32:23-31.

51. Tousoulis D, Davies G, Stefanadis C, Toutouzas P, Ambrose JA. Inflammatory and thrombotic mechanisms in coronary atherosclerosis. Heart, 2003;89:993-997. Epub 2003/08/19.

52. Sakai T, Inoue S, Takei M, Ogawa G, Hamazaki Y, Ota H, Koboyashi Y. Activated inflammatory cells participate in thrombus size through tissue factor and plasminogen activator inhibitor-1 in acute coronary syndrome: Immunohistochemical analysis. Thrombosis Research, 2011;127:443-449.

53. Nosaka M, Ishida $\mathrm{Y}$, Kimura A, Kondo $\mathrm{T}$. Time-dependent appearance of intrathrombus neutrophils and macrophages in a stasis-induced deep vein thrombosis model and its application to thrombus age determination. Int $\mathrm{J}$ Legal Med, 2009; 123:235-240.

54. Marzilli M, Orsini E, Marraccini P, Testa R. Beneficial effects of intracoronary adenosine as an adjunct to primary angioplasty in acute myocardial infarction. Circulation, 2000;101:2154-2159.

55. Nylander S, Femia E, Scavone M, Berntsson P, Asztély AK, Nelander K, Löfgren L, Nilsson R, Cattaneo M. Ticagrelor inhibits human platelet aggregation via adenosine in addition to P2Y12 antagonism. Journal of Thrombosis and Haemostasis, 2013;11:1867-1876. 